\title{
Sex differences in mineralocorticoid receptor antagonist trials: a pooled analysis of three large clinical trials
}

Short tittle: Sex differences in MRA trials

Xavier Rossello, MD, PhD ${ }^{1,2,3}$; João Pedro Ferreira, MD, PhD"; Stuart J Pocock, PhD5 John JV McMurray, MD, $\mathrm{PhD}^{6}$; Scott D. Solomon, MD, $\mathrm{PhD}^{7}$; Carolyn SP Lam, MD, PhD' ; Nicolas Girerd, MD, $\mathrm{PhD}^{4}$; Bertram Pitt, MD, $\mathrm{PhD}^{9}$; Patrick Rossignol, MD, PhD ${ }^{4}$; Faiez Zannad, MD, $\mathrm{PhD}^{4}$

${ }^{1}$ Department of Cardiology, Hospital Universitari Son Espases (HUSE), Mallorca, Spain; ${ }^{2}$ Centro Nacional de Investigaciones Cardiovasculares Carlos III (CNIC), Madrid, Spain;3 CIBER de enfermedades CardioVasculares (CIBERCV), Madrid, Spain; ${ }^{4}$ Université de Lorraine, Centre d'Investigation CliniquePlurithématique Inserm CIC-P 1433, and Inserm U1116, CHRU Nancy Brabois, F-CRIN INI-CRCT (Cardiovascular and Renal Clinical Trialists), Nancy, France; ${ }^{5}$ London School of Hygiene and Tropical Medicine, London, United Kingdom; ${ }^{6}$ BHF Cardiovascular Research Centre, University of Glasgow, Glasgow, Scotland, UK; ${ }^{7}$ Cardiovascular Division, Brigham and Women's Hospital, Boston, Massachusetts, MA, USA $;^{8}$ National Heart Centre Singapore, Singapore; ${ }^{9}$ Department of Medicine, University of Michigan School of Medicine, Ann Arbor, USA

Abstract word count: 248

Manuscript word count: 3185

\section{Address for correspondence}

Dr. Faiez Zannad, Centre d’Investigations Cliniques - INSERM CHU de Nancy, Institut Lorrain du Coeur et des Vaisseaux Louis Mathieu, 4 Rue du Morvan, Vandoeuvre lès Nancy 54500, France.

Tel: +33 383157322/20 ; Fax: +33 383157324; Email: f.zannad@chu-nancy.fr

This is the author manuscript accepted for publication and has undergone full peer review but has not been through the copyediting, typesetting, pagination and proofreading process, which may lead to differences between this version and the Version of Record. Please cite this article as doi: 10.1002/ejhf.1740

This article is protected by copyright. All rights reserved. 


\section{Abstract}

AIMS. Women with heart failure (HF) are under-represented in individual randomized clinical trials (RCTs). Little is known about sex-specific treatment effects in HF medications. We evaluated sex differences in the response to mineralocorticoid receptor antagonists (MRAs) in major HF MRA trials, including a broad spectrum of left ventricular ejection fraction (LVEF).

METHODS AND RESULTS. Individual-patient data fixed-effect meta-analysis was performed using 6,167 patients (31.4\% were women) recruited in three placebo-controlled RCTs: Randomized Aldactone Evaluation Study (RALES), Eplerenone in Mild Patients Hospitalization and Survival Study in Heart Failure (EMPHASIS-HF) and the Spironolactone for Heart Failure with Preserved Ejection Fraction (TOPCAT)-Americas. Compared to men, women were older, had higher body mass index and lower glomerular filtration rate. They also had higher LVEF and poorer NHYA functional class and were less likely to be taking angiotensin-converting enzyme inhibitors/angiotensin-II receptor blockers. Placebo-arm event rates were lower for women compared with men (15.4 vs. 22.1 per 100-person-year; $\mathrm{p}=0.002)$. MRAs reduced consistently, in men and women, the relative risk for cardiovascular death or heart failure hospitalization (p-for-interaction=0.83), cardiovascular death (p-for-interaction=0.44) and all-cause death (p-for-interaction=0.19). These findings remained consistent after adjustment for potential confounders, regardless of the LVEF. There was no sex-specific impact of MRA on the rate of hyperkalemia and worsening renal function during the median 22 months of follow-up.

This article is protected by copyright. All rights reserved. 
CONCLUSION. In three large MRA RCTs, women were substantially different than men with regards to their clinical features and event rates. Nonetheless, this meta-analysis supports a consistent and beneficial MRA effect regardless of sex.

\section{Keywords}

Heart failure; mineralocorticoid receptor antagonists; meta-analysis; women

This article is protected by copyright. All rights reserved. 


\section{Introduction}

Current guidelines recommend the use of mineralocorticoid receptor antagonists (MRAs) in patients with symptomatic heart failure (HF), left ventricular ejection fraction (LVEF) $\leq 35 \%$ and New York Heart Association (NYHA) class II-IV, based on the results of the Randomized Aldactone Evaluation Study (RALES) ${ }^{1}$ and the Eplerenone in Mild Patients Hospitalization and Survival Study in Heart Failure trial (EMPHASIS-HF) ${ }^{2}$, supported by the findings of the Eplerenone Post-Acute Myocardial Infarction Heart Failure Efficacy and Survival Study (EPHESUS) trial ${ }^{3}$. Treatment with spironolactone did not show a reduction in the incidence of the time-to-first composite of cardiovascular death, aborted cardiac arrest or HF hospitalizations in patients with $\mathrm{LVEF} \geq 45 \%$ in the Spironolactone for Heart Failure with Preserved Ejection Fraction (TOPCAT) trial ${ }^{4}$; however, important regional differences in patient characteristics, event-rates, drug adherence and treatment effect were identified. Patients in two countries (Georgia and Russia) had low event rates, inconsistent with HFpEF and adherence in those countries was poorer than elsewhere ${ }^{5-7}$.

Some controversy has arisen in HF pharmacotherapy in light of the recent findings provided by the Prospective Comparison of ARNI [angiotensin receptor-neprilysin inhibitor] with ARB [angiotensin-receptor blockers] Global Outcomes in HF with Preserved Ejection Fraction (PARAGON-HF) trial, where a subgroup analysis suggested an heterogeneity of treatment effect with possible benefit of ARNI in women compared to men ${ }^{8}$. These findings should be considered in the context of the Prospective Comparison of ARNI with ACEI [Angiotensin-Converting-Enzyme Inhibitor] to Determine Impact on Global Mortality and Morbidity in Heart Failure Trial (PARADIGM-HF) trial, which had nearly identical entry 
criteria apart from a lower LVEF and showed no interaction in treatment effect between women and men ${ }^{9}$.

There are many differences between men and women with $\mathrm{HF}^{10}$. Women with HFrEF have a better survival than men with the same condition and the same is true for HFpEF ${ }^{11,12}$. Moreover, women are, on average, older than men, have less coronary heart disease but more hypertension ${ }^{11,12}$. They have also worse symptoms and worse renal function and receive less evidence-based therapy than men ${ }^{13}$. These differences raise the possibility of a difference between men and women in relation to the efficacy or tolerability of HF treatments, such as ARNI or MRAs. This possibility has been difficult to evaluate as subgroups in individual trials are, by definition, underpowered, especially as women represent the minority of patients $^{14,15}$. A meta-analytical approach helps mitigate this limitation.

We performed a meta-analysis, using individual patient data from three large randomized clinical trials (RALES, EMPHASIS-HF and TOPCAT), to assess the sex-specific responses to MRA treatment in individuals with HF across a broad spectrum of ejection fraction.

\section{Methods}

\section{Study design, setting and participants}

We pooled data from three placebo-controlled RCTs: RALES (NYHA class III-IV with LVEF $\leq 35 \%)^{1}$, EMPHASIS-HF (NYHA class II with LVEF $\left.\leq 35 \%\right)^{2}$ and TOPCAT (heart failure signs and symptoms with $\mathrm{LVEF} \geq 45 \%)^{4}$. Table S1 shows the main features of each trial, including inclusion/exclusion criteria, medication (spironolactone or eplerenone),

This article is protected by copyright. All rights reserved. 
primary endpoint and duration of follow-up. Given regional disparities described in TOPCAT, subsequent post hoc analyses of TOPCAT have been restricted to the patients randomized in other countries (all in Latin and North America) $)^{6,7}$, where patients had characteristics compatible with HFpEF and high proportion of detectable circulating levels of spironolactone metabolites. Therefore, we used only data from the "Americas” (United States, Canada, Brazil, and Argentina), excluding those from Russia and Georgia.

Each individual RCT was conducted in accordance with the Declaration of Helsinki ${ }^{16}$ and approved by site ethics committees. All participants gave written informed consent to participate in the RCTs.

\section{Study outcomes}

The primary outcome used in the present analysis was the composite of cardiovascular death or HF hospitalization. Secondary outcomes included cardiovascular death and all-cause mortality. These clinical outcomes were centrally adjudicated by endpoint committees with broadly consistent definitions across the trials ${ }^{1,2,4}$.

Hyperkalemia was defined as any laboratory value of serum potassium above 5.5 $\mathrm{mmol} / \mathrm{L}$ during follow-up and worsening renal function was defined as a decline of more than $30 \%$ in estimated glomerular filtration rate (eGFR) during follow-up.

\section{Statistical analysis}

Baseline clinical features between men and women were described as frequency (\%) and compared using chi-square tests for categorical data, whereas baseline continuous data were expressed as mean and standard deviation (SD) and compared using t tests. The normal distribution of continuous data subset was evaluated using graphical methods. 
Incidence rates for men and women (in each of the two treatment groups), as well as incidence rates ratios (for estimating relative risk reduction) and difference in rates (for estimating absolute risk reduction) were estimated for each HF phenotype and for the overall pooled sample. The number needed to treat (NNT) at 3 years was estimate using the inverse of the absolute risk reduction and their 95\% confidence interval (95\% CI).

Baseline time was defined by the timing of randomization (Table S1), which was (1) within 6 months of meeting the inclusion criteria for RALES; (2) within 6 months after hospitalization for a cardiovascular reason for EMPHASIS-HF; and (3) within 12 months after hospitalization for heart failure or with an elevated natriuretic peptide level within 60 days before randomization (brain $\mathrm{BNP} \geq 100 \mathrm{pg} / \mathrm{mL}$ or NTproBNP $\geq 360 \mathrm{pg} / \mathrm{mL}$ ). KaplanMeier curves for the composite endpoint of cardiovascular death or heart failure hospitalization were obtained for each subgroup (male-placebo, male-MRA, female-placebo and female-MRA) within each HF phenotype using the Kaplan-Meier method. Cox proportional hazards modelling was used to assess the treatment effect in the overall pooled sample as well as to explore whether this effect was consistent between men and women (adding the interaction MRA * gender) into the model and reporting the p for interaction. Hazard ratios (HRs) with their 95\% CI were used for treatment effect estimates. The model was stratified by study, which assumes equal effects across strata but with a baseline hazard unique to each study ${ }^{17,18}$.

A fixed-effect model for a one-stage individual patient data meta-analysis was conducted based on the assumption that the underlying relative treatment effect was similar across trials ${ }^{19}$. In order to obtain an adjusted estimate of the effect of MRA for men and 
women separately, a set of covariates were chosen according to their clinical relevance or historical association with the outcome in previous studies ${ }^{18,20}$ : MRA, gender, age, race, systolic blood pressure, diabetes, hypertension, atrial fibrillation, ischemic cause, NYHA class III-IV, LVEF, potassium, eGFR, diuretics, ACEI or ARB, beta-blockers and the interaction (MRA $x$ gender). Further subgroup evaluations for the primary outcome were performed with a Cox model stratified by study, using the adjusted model and adding a threeway interaction for three clinically relevant patient subsets (age >75 y.o, diabetes and eGFR<60).

Visual inspection of individual effect sizes and overall effect size estimations and their 95\% CI were used to identify substantial variation in treatment effect estimates across trials beyond the variation expected by chance alone (statistical heterogeneity). Heterogeneity was formally tested using a 2 degree of freedom Wald test of the overall interaction study $x$ treatment $x$ gender.

Logistic regression models were used to assess whether the number of adverse events (hyperkalemia and worsening renal function) were consistent between men and women at the end of the follow-up. An interaction term (MRA x gender) was used to report whether adverse events differed by gender and the statistical significance was determined by the relevant $\mathrm{p}$ for interaction.

The two-tailed significance level was set at 5\%. STATA software version 15.1 (Stata Corp, College Station, TX, USA) was used to perform the analyses and produce most graphs. XR had full access to all the data in the study and takes responsibility for its integrity and the data analysis.

This article is protected by copyright. All rights reserved. 


\section{Results}

\section{Sex differences in baseline variables}

Individual patient data from the three randomised trials (RALES, EMPHASIS-HF and TOPCAT-Americas) were available for 6,167 patients. Of these, 4,229 (68.6\%) were men (2,127 and 2,102 randomly allocated to placebo and MRA, respectively) and 1,938 (31.4\%) were women (968 and 970 randomly assigned to placebo and MRA, respectively). The median follow-up was 22 months (interquartile range 9-33 months) (the individual follow-up times of each RCT are given in Table S1).

Baseline clinical features, medical history, laboratory findings and background treatment at randomization, according to sex, are shown in Table 1. Generally, women were older (35.4\% vs $25.3 \%$ were $>75$ years) and had higher BMI and poorer renal function ( $51.8 \%$ vs $38.3 \%$ had eGFR $<60 \mathrm{ml} / \mathrm{min} / 1.73 \mathrm{~m}^{2}$ ). Women more frequently had a history of hypertension, but less often a history of MI, atrial fibrillation and COPD. Women also had a significantly higher mean LVEF (32.3\% vs 41.7\%) and poorer overall NHYA functional class. They were also less likely to be treated with an ACEI or ARB (86.0\% vs $90.6 \%)$, but there were no significant differences between men and women regarding beta blocker and diuretic use. These data stratified by HF type (HFrEF vs HFpEF) are presented in Table S2.

\section{Unadjusted treatment effect}

Overall and by-HF phenotype Kaplan-Meier curves for cardiovascular death or heart failure requiring hospitalization are described in Figure 1 and Figure 2, respectively. The unadjusted incidence rate ratios and incidence rate differences are shown in Table 2. The

This article is protected by copyright. All rights reserved. 
effect of MRA therapy on the primary outcome was consistent between men and women overall and within each HF phenotype, though the relative risk reduction was greater in HFrEF compared with HFpEF. Consequently, the "absolute “ reduction in number of events was greater in the subset of patients from RALES (NYHA III-IV; LVEF $\leq 35 \%$ ) and EMPHASIS-HF (NYHA II, LVEF $\leq 35 \%$ ) in comparison to those in TOPCAT-Americas ( $L V E F \geq 45 \%$ ), although the effect did not differ between men and women within each trial cohort (Table S2).

After pooling the data, the primary outcome of cardiovascular death or HF hospitalization occurred in 798 men (37.5\%) and 330 women (34.1\%) taking placebo ( $\mathrm{p}=0.002)$, and in 602 men (28.6\%) and 251 women (25.9\%) taking a MRA. The overall unadjusted HR (95\% CI) was 0.70 (0.64-0.76), and was consistent between men (HR 0.69; 95\% CI: 0.62-0.77) and women (HR 0.71; 95\% CI: 0.60-0.83), as shown in Figure 3 (p for interaction 0.83 ). The overall absolute risk reduction of the primary composite outcome at 3 years was $10 \%$, which provides an NNT of 10 (95\% CI: 8-14) patients at 3 years to avoid one event, and was consistent between men (NNT 10; 95\% CI: 8-15) and women (NNT 10; 95\% CI: 7-19).

The risk reductions in secondary outcomes were also relatively consistent between men and women (Tables 3 and Table 4). For cardiovascular death, the unadjusted HR (95\% CI) was $0.75(0.65-0.86)$ for men and $0.67(0.54-0.85)$ for women (p for interaction 0.44$)$, whereas for all-cause mortality the unadjusted HR (95\% CI) was $0.80(0.71-0.90)$ for men and $0.69(0.56-0.84)$ for women (p for interaction 0.19). 


\section{Adjusted treatment effect}

After adjustment for baseline co-variates (gender, age, race, systolic blood pressure, diabetes, hypertension, atrial fibrillation, non-ischemic cause, NYHA class III-IV, LVEF, potassium, estimated glomerular filtration rate, diuretics, ACEI or ARB treatment, beta-blocker treatment), the treatment effect remained relatively consistent between men and women and within the HFrEF and HFpEF phenotypes (Figure 3): the MRA vs placebo HR (95\% CI) was $0.65(0.58-0.74)$ for men and 0.67 (0.54-0.83) for women with HFrEF and 0.85 (0.67-1.08) for men and 0.83 (0.64-1.07) for women with HFpEF . In the adjusted analysis of all patients, irrespective of LVEF, MRA treatment reduced the risk of cardiovascular death or heart failure hospitalization by $31 \%$ in men (HR=0.69; $95 \% \mathrm{CI}$ : $0.62-0.77$ ) and by $27 \%$ in women (HR=0.73; 95\% CI: 0.62-0.86).

\section{Statistical heterogeneity}

The individual effect size for each trial and overall effect size estimations and their 95\% CI depicted in Figure S1 already suggest the lack of substantial statistical heterogeneity between RALES and EMPHASIS-HF cohorts. Similarly, the individual effect size for HFrEF and HFpEF subject depicted in Table 2 and Figure 3 also suggest lack of statistical heterogeneity. The hypothesis of little heterogeneity is also supported by the Wald test for overall interaction study $x$ treatment $x$ gender $(\mathrm{p}=0.61)$.

\section{Subgroup analyses}

Treatment effect was consistent between men and women across the three prespecified subgroups examined i.e. age $>75$ vs age $\leq 75$ years, diabetes vs no diabetes and eGFR $<60$ vs eGFR $\geq 60 \mathrm{ml} / \mathrm{min} / 1.73 \mathrm{~m}^{2}$ after adjustment for baseline covariates (Figure 4).

This article is protected by copyright. All rights reserved. 


\section{Adverse event effects}

Differences in adverse events between men and women were consistent across treatment arms (Table 5). There were no significant sex-related differences in the rate of hyperkalemia either in the placebo arm or the MRA arm ( $\mathrm{p}$ for interaction $=0.94$ ). By contrast, women more often had worsening renal function over follow-up in the placebo arm, though the between treatment group differences were similar by sex ( $\mathrm{p}$ for interaction $=0.81$ ).

\section{Discussion}

In this meta-analysis using individual patient-level data, including 6,167 subjects, representing the full spectrum of LVEF, we found that: 1) women differed substantially from men with respect to baseline characteristics (they were older, had a higher BMI, poorer renal function and fewer co-morbidities, except for hypertension), had a higher mean LVEF, poorer NHYA functional class and were less likely to be treated with an ACEI or ARB); 2) men were at higher risk of events than women; 3) MRA consistently reduced the risk for cardiovascular death and heart failure hospitalization after a mean follow-up of 22 months; 4) by-sex treatment effect remained consisted after adjustment for potential confounders, confirming the lack of interaction between treatment effect and sex; 5) treatment effect was consistent between men and women across the three subgroups of patients studied (age $>75$, diabetes and eGFR<60) after adjustment for baseline covariates; and 6) there was no sexspecific impact of MRA on hyperkalemia and worsening renal function.

Men and women differ in relation to the physiology of their cardiovascular system (i.e. body composition and role of hormonal changes ${ }^{21}$ ), in risk factors for cardiovascular 
disease, presentation with cardiovascular disease and outcomes from cardiovascular disease. Moreover, there are also sex-related differences in the pharmacokinetics and pharmacodynamics among some of widely used cardiovascular drugs ${ }^{10,22}$. Thus, it is important to understand the sex-specific efficacy and tolerability of any therapy for cardiovascular disease. However, this type of analysis requires a dataset large enough to give statistically powered information. This issue is illustrated by the results of early trials with ACEI suggesting a benefit only in men ${ }^{22}$, when subsequent meta-analyses with greater statistical power showed no sex-related difference in treatment effect ${ }^{23}$. In contrast, we have incipient but apparently contradictory information from a younger drug (ARNI) in HFpEF: the PARAGON-HF trial reported a subgroup analysis suggesting an heterogeneity of treatment effect with possible benefit of ARNI in women with respect to men (rates ratios of 0.73 and 1.03 for the composite outcome of total hospitalizations for heart failure and

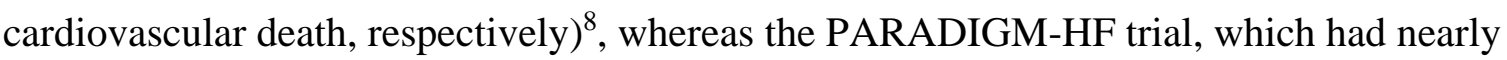
identical entry criteria apart from a lower LVEF, showed no interaction in treatment effect between women and men ${ }^{9}$. Notably, women (who represent a high proportion of HFpEF proportion of patients) were far more represented in the PARAGON-HF trial (51.7\%) in comparison to the PARADIGM-HF trial (21.8\%), though absolute numbers were more similar between trials. Importantly, we found that the benefit of MRA therapy was consistent between men and women across three large RCTs.

In line with the previous reports ${ }^{11-13,24}$, and as described above, there were many differences in the baseline characteristics of men and women. Our baseline characteristics data match those reported in the "real-world" by the Swedish Heart Failure Registry ${ }^{15}$ : 
women were older, and more symptomatic and more likely to have hypertension and poor renal function than men. Despite they show that women had a higher crude risk of mortality and morbidity in $\mathrm{HFpEF}^{15}$, their results after adjustment are in line with our findings showing that women have a lower crude risk for poor outcomes regardless of LVEF, though less differences between men and women are observed in our HFrEF subset of patients. Importantly, the treatment benefit of MRA therapy did not change substantially after adjusting for these and other potential confounders, which have an impact on clinical outcomes and are unevenly distributed between men and women.

At first sight, our results appear to contradict a recent secondary analysis from the TOCAT-Americas suggesting a potential reduction in all-cause mortality associated with spironolactone in women that was not observed in men after adjustment for potential confounding (HR were 0.66 and 1.06 for women and men, respectively; p for interaction $0.024)^{25}$. Of note, this analysis did not find a significant interaction for the primary endpoint or other outcomes, including cardiovascular mortality, which seems much more appropriate to study the treatment effect provided by MRA, as we should expect little gain on noncardiovascular causes of death by administering MRAs. It is likely that this reflects a spurious, chance-finding reflecting the small numbers of events in the TOPCAT-Americas analysis, a conclusion supported by the finding of a mortality benefit from MRA therapy in our much larger and statistically more robust study. A different pathophysiology in women ${ }^{10-}$ 12 or a simple regression to the mean might other less likely explanations for the disagreement between our findings and those reported by Merrill and colleagues ${ }^{25}$. Some ongoing studies, such as the Spironolactone Initiation Registry Randomized Interventional 
Trial in Heart Failure with Preserved Ejection Fraction (SPIRRIT) (NCT02901184) and the SPIRonolactone In the Treatment for Heart Failure (SPIRIT-HF) (EudraCT 2017-000697-11) may shed some light on the issue of whether MRA has a different treatment effect between men and women in HFpEF.

We examined 3 clinically important subgroups of patients at particularly high risk of events and in which there is often concern about using MRA therapy i.e. the elderly, patients with diabetes and those with a low eGFR. We found that there was no evidence of a sexrelated difference in either the efficacy or safety of MRA therapy in these subgroups.

In line with previous reports ${ }^{26}$, our findings on adverse event effects underscore the need to measure serum potassium and creatinine levels serially and to accordingly adjust the dose of MRA regardless the gender of the patient. Other factors, such as the eGFR, have a greater impact on the rate of side-effects and drug discontinuation and should be taken into account to adjust for the dose of MRAs, and more broadly RAASi ${ }^{27,28}$.

\section{Study limitations}

We did not include a number of small trials which studied MRA treatment in patients with HF, because these had few events and are unlikely to alter our conclusions. We also combined two HFrEF trials with a HFpEF trials when these two HF phenotypes are distinct and do not respond to all therapies in a similar manner. Finally, our results are based on the assumption that MRAs represent a 'class effect' ${ }^{29}$, although spironolactone and eplerenone differ in their molecular structure, pharmacokinetics and pharmacodynamics. 


\section{Conclusions}

In this large meta-analysis using individual patient data, women were substantially different from men with regards to their clinical features and events. Nevertheless, MRA treatment led to consistent reductions in the risk for cardiovascular death and heart failure hospitalization, cardiovascular death alone and all-cause death, in both men and women, regardless their NYHA class, LVEF and other confounding factors. Treatment-related hyperkalemia and worsening renal function did not vary by sex. Both men and women can benefit from optimizing the use of an MRA treatment, which is commonly underused in routine practice. These findings are particularly important in the light of recent findings suggesting a different treatment effect between men and women with some HF drugs, such as ARNI.

This article is protected by copyright. All rights reserved. 


\section{Funding}

XR has received support from SEC-CNIC CARDIOJOVEN Program. JF, NG, PR, FZ are supported by the French National Research Agency Fighting Heart Failure (ANR-15-RHU0004), by the French PIA project «Lorraine Université d’Excellence » GEENAGE (ANR-15IDEX-04-LUE) programs, and the Contrat de Plan Etat Région Lorraine and FEDER IT2MP.

\section{Conflict of interest}

XR, JPF and SJP have nothing to disclose. JMcM reports conflicts of interest from Roche Pharmaceuticals, during the conduct of the study; other from Novartis, Cardiorentis, Amgen Oxford University/Bayer, GlaxoSmithKline, Theracos, Abbvie, Dal-Cor, Pfizer, Merck, AstraZeneca Bristol Myers Squibb (BMS), Kidney Research UK (KRUK)/Kings College Hospital, London/Vifor-Fresenius Pharma, outside the submitted work.SS has received research grants from Alnylam, Amgen, AstraZeneca, Bellerophon, Bayer, BMS, Celladon, Cytokinetics, Eidos, Gilead, GSK, Ionis, Lone Star Heart, Mesoblast, MyoKardia, NIH/NHLBI, Novartis, Sanofi Pasteur, Theracos, and has consulted for Akros, Alnylam, Amgen, Arena, AstraZeneca, Bayer, BMS, Cardior, Corvia, Cytokinetics, Daiichi-Sankyo, Gilead, GSK, Ironwood, Merck, Myokardia, Novartis, Roche, Takeda, Theracos, Quantum Genetics, Cardurion, AoBiome, Janssen, Cardiac Dimensions, Tenaya. CSPL is supported by a Clinician Scientist Award from the National Medical Research Council of Singapore; has received research support from Boston Scientific, Bayer, Roche Diagnostics, AstraZeneca, Medtronic, and Vifor Pharma; has served as consultant or on the Advisory Board/ Steering 
Committee/ Executive Committee for Boston Scientific, Bayer, Roche Diagnostics, AstraZeneca, Medtronic, Vifor Pharma, Novartis, Amgen, Merck, Janssen Research \& Development LLC, Menarini, Boehringer Ingelheim, Novo Nordisk, Abbott Diagnostics, Corvia, Stealth BioTherapeutics, JanaCare, Biofourmis, Darma, Applied Therapeutics, WebMD Global LLC, Radcliffe Group Ltd and Corpus. NG received board fees from Novartis and honoraria from Boehringer. BP has received personal fees from Bayer, Astra Zeneca , Sanofi, KBP pharmaceuticals *, Sarfez*, scPharmaceuticals*, Cereno *, SQinnovations * , Relypsa/Vifor *, G3 Pharma*and Ardelyx . In addition, BP has a US Patent 99131412-site specific delivery of eplerenone to the myocardium. PR reports personal fees (consulting) from Corvidia, Novartis, NovoNordisk, Relypsa, AstraZeneca, G3P, Grünenthal, Idorsia, Stealth Peptides, Fresenius, Vifor; and lecture fees from Ablative Solutions, Bayer, and CVRx; cofounder of CardioRenal. FZ reports consultancy, trials oversight committees and/or speaker fees from Actelion, Amgen, Applied Therapeutics, AstraZeneca, Bayer, Boehringer, Boston Scientific, Cardior, Cereno Scientific AB, CEVA, Cirius Therapeutics, CVRx,, G3 Pharma, GE Healthcare, J\&J, Livanova, Merck, Mundipharma, Novartis, NovoNordisk, Pfizer, Quantum Genomics, Relypsa, Resmed, ViforFresenius, ZS Pharma, and is founder of CardioRenal, CVCT and Eshmoun.

* for stock options 


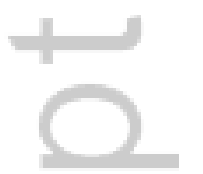

This article is protected by copyright. All rights reserved. 


\section{References}

1. Pitt B, Zannad F, Remme WJ, Cody R, Castaigne A, Perez A, Palensky J, Wittes J. The effect of spironolactone on morbidity and mortality in patients with severe heart failure. Randomized Aldactone Evaluation Study Investigators. N Engl J Med 1999;341:709-717.

2. Zannad F, McMurray JJ V, Krum H, Veldhuisen DJ van, Swedberg K, Shi H, Vincent J, Pocock SJ, Pitt B, EMPHASIS-HF Study Group. Eplerenone in patients with systolic heart failure and mild symptoms. N Engl J Med 2011;364:11-21.

3. Pitt B, Remme W, Zannad F, Neaton J, Martinez F, Roniker B, Bittman R, Hurley S, Kleiman J, Gatlin M, Eplerenone Post-Acute Myocardial Infarction Heart Failure Efficacy and Survival Study Investigators. Eplerenone, a selective aldosterone blocker, in patients with left ventricular dysfunction after myocardial infarction. $N$ Engl J Med 2003;348:1309-1321.

4. Pitt B, Pfeffer MA, Assmann SF, Boineau R, Anand IS, Claggett B, Clausell N, Desai AS, Diaz R, Fleg JL, Gordeev I, Harty B, Heitner JF, Kenwood CT, Lewis EF, O’Meara E, Probstfield JL, Shaburishvili T, Shah SJ, Solomon SD, Sweitzer NK, Yang S, McKinlay SM, TOPCAT Investigators. Spironolactone for Heart Failure with Preserved Ejection Fraction. N Engl J Med 2014;370:1383-1392.

5. Ferreira JP, Girerd N, Rossignol P, Zannad F. Geographic differences in heart failure trials. Eur J Heart Fail 2015;17:893-905.

6. Pfeffer MA, Claggett B, Assmann SF, Boineau R, Anand IS, Clausell N, Desai AS, Diaz R, Fleg JL, Gordeev I, Heitner JF, Lewis EF, O’Meara E, Rouleau J-L, 
Probstfield JL, Shaburishvili T, Shah SJ, Solomon SD, Sweitzer NK, McKinlay SM, Pitt B. Regional Variation in Patients and Outcomes in the Treatment of Preserved Cardiac Function Heart Failure With an Aldosterone Antagonist (TOPCAT) Trial. Circulation 2015;131:34-42.

7. Denus S de, O’Meara E, Desai AS, Claggett B, Lewis EF, Leclair G, Jutras M, Lavoie J, Solomon SD, Pitt B, Pfeffer MA, Rouleau JL. Spironolactone Metabolites in TOPCAT — New Insights into Regional Variation. N Engl J Med 2017;376:1690_ 1692.

8. Solomon SD, McMurray JJV, Anand IS, Ge J, Lam CSP, Maggioni AP, Martinez F, Packer M, Pfeffer MA, Pieske B, Redfield MM, Rouleau JL, Veldhuisen DJ van, Zannad F, Zile MR, Desai AS, Claggett B, Jhund PS, Boytsov SA, Comin-Colet J, Cleland J, Düngen H-D, Goncalvesova E, Katova T, Kerr Saraiva JF, Lelonek M, Merkely B, Senni M, Shah SJ, Zhou J, et al. Angiotensin-Neprilysin Inhibition in Heart Failure with Preserved Ejection Fraction. $N$ Engl J Med Massachusetts Medical Society; 2019;381:1609-1620.

9. McMurray JJV, Packer M, Desai AS, Gong J, Lefkowitz MP, Rizkala AR, Rouleau JL, Shi VC, Solomon SD, Swedberg K, Zile MR. Angiotensin-neprilysin inhibition versus enalapril in heart failure. N Engl J Med 2014;371:993-1004.

10. Santema BT, Ouwerkerk W, Tromp J, Sama IE, Ravera A, Regitz-Zagrosek V, Hillege H, Samani NJ, Zannad F, Dickstein K, Lang CC, Cleland JG, Maaten JM Ter, Metra M, Anker SD, Harst P van der, Ng LL, Meer P van der, Veldhuisen DJ van, Meyer S, Lam CSP, Voors AA, Richards AM, Lam CSP, Anand I, Hung C-L, Ling LH, Liew 
HB, Narasimhan C, Ngarmukos T, et al. Identifying optimal doses of heart failure medications in men compared with women: a prospective, observational, cohort study. Lancet 2019;394:1254-1263.

11. O’Meara E, Clayton T, McEntegart MB, McMurray JJ V, Piña IL, Granger CB, Ostergren J, Michelson EL, Solomon SD, Pocock S, Yusuf S, Swedberg K, Pfeffer MA, CHARM Investigators. Sex differences in clinical characteristics and prognosis in a broad spectrum of patients with heart failure: results of the Candesartan in Heart failure: Assessment of Reduction in Mortality and morbidity (CHARM) program. Circulation 2007;115:3111-3120.

12. Martínez-Sellés M, Doughty RN, Poppe K, Whalley GA, Earle N, Tribouilloy C, McMurray JJ V, Swedberg K, Køber L, Berry C, Squire I, Meta-Analysis Global Group In Chronic Heart Failure (MAGGIC). Gender and survival in patients with heart failure: interactions with diabetes and aetiology. Results from the MAGGIC individual patient meta-analysis. Eur J Heart Fail 2012;14:473-479.

13. Yancy CW, Fonarow GC, Albert NM, Curtis AB, Stough WG, Gheorghiade M, Heywood JT, McBride ML, Mehra MR, O’Connor CM, Reynolds D, Walsh MN. Influence of patient age and sex on delivery of guideline-recommended heart failure care in the outpatient cardiology practice setting: Findings from IMPROVE HF. Am Heart J 2009;157:754-762.

14. Rossello X, Pocock SJ, Julian DG. Long-Term Use of Cardiovascular Drugs. J Am Coll Cardiol 2015;66:1273-1285.

15. Stolfo D, Uijl A, Vedin O, Strömberg A, Faxén UL, Rosano GMC, Sinagra G, 
Dahlström U, Savarese G. Sex-Based Differences in Heart Failure Across the Ejection Fraction Spectrum: Phenotyping, and Prognostic and Therapeutic Implications. JACC Hear Fail 2019;7:505-515.

16. Rickham PP. Human Experimentation. Code Of Ethics Of The World Medical Association. Declaration Of Helsinki. Br Med J 1964;2:177.

17. Riley RD, Lambert PC, Abo-Zaid G. Meta-analysis of individual participant data: rationale, conduct, and reporting. BMJ 2010;340:c221.

18. Rossello X, Ariti C, Pocock SJ, Ferreira JP, Girerd N, McMurray JJ V., Veldhuisen DJ Van, Pitt B, Zannad F. Impact of mineralocorticoid receptor antagonists on the risk of sudden cardiac death in patients with heart failure and left-ventricular systolic dysfunction: an individual patient-level meta-analysis of three randomized-controlled trials. Clin Res Cardiol 2019;108:477-486.

19. Costa BR da, Jüni P. Systematic reviews and meta-analyses of randomized trials: principles and pitfalls. Eur Heart J 2014;41:3336-3345.

20. Rossignol P, Girerd N, Bakris G, Vardeny O, Claggett B, McMurray JJ V, Swedberg K, Krum H, Veldhuisen DJ van, Shi H, Spanyers S, Vincent J, Fay R, Lamiral Z, Solomon SD, Zannad F, Pitt B. Impact of eplerenone on cardiovascular outcomes in heart failure patients with hypokalaemia. Eur J Heart Fail 2017;19:792-799.

21. Fischer M, Baessler A, Schunkert H. Renin angiotensin system and gender differences in the cardiovascular system. Cardiovasc Res 2002;53:672-677.

22. Tamargo J, Rosano G, Walther T, Duarte J, Niessner A, Kaski J, Ceconi C, Drexel H, Kjeldsen K, Savarese G, Torp-Pedersen C, Atar D, Lewis B, Agewall S. Gender

This article is protected by copyright. All rights reserved. 
differences in the effects of cardiovascular drugs. Eur Hear J - Cardiovasc Pharmacother 2017;3:163-182.

23. Garg R, Yusuf S. Overview of randomized trials of angiotensin-converting enzyme inhibitors on mortality and morbidity in patients with heart failure. Collaborative Group on ACE Inhibitor Trials. JAMA 1995;273:1450-1456.

24. Rossello X, Ferreira JP, McMurray JJ, Aguilar D, Pfeffer MA, Pitt B, Dickstein K, Girerd N, Rossignol P, Zannad F, High-Risk Myocardial Infarction Database Initiative. Impact of insulin-treated diabetes on cardiovascular outcomes following high-risk myocardial infarction. Eur Hear J Acute Cardiovasc Care 2019;8:231-241.

25. Merrill M, Sweitzer NK, Lindenfeld J, Kao DP. Sex Differences in Outcomes and Responses to Spironolactone in Heart Failure With Preserved Ejection Fraction: A Secondary Analysis of TOPCAT Trial. JACC Heart Fail 2019;7:228-238.

26. Eschalier R, McMurray JJV, Swedberg K, Veldhuisen DJ van, Krum H, Pocock SJ, Shi H, Vincent J, Rossignol P, Zannad F, Pitt B. Safety and Efficacy of Eplerenone in Patients at High Risk for Hyperkalemia and/or Worsening Renal Function. J Am Coll Cardiol 2013;62:1585-1593.

27. Ferreira JP, Abreu P, McMurray JJ V, Veldhuisen DJ van, Swedberg K, Pocock SJ, Vincent J, Lins K, Rossignol P, Pitt B, Zannad F. Renal function stratified dose comparisons of eplerenone versus placebo in the EMPHASIS-HF trial. Eur J Heart Fail 2019;21:345-351.

28. Rossignol P, Hernandez AF, Solomon SD, Zannad F. Heart failure drug treatment. Lancet 2019;393:1034-1044.

This article is protected by copyright. All rights reserved. 
29. Iqbal J, Parviz Y, Pitt B, Newell-Price J, Al-Mohammad A, Zannad F. Selection of a mineralocorticoid receptor antagonist for patients with hypertension or heart failure. Eur J Heart Fail 2014;16:143-150. 


\section{Figure legends}

Figure 1. Kaplan-Meier survival curve for cardiovascular death (CVD) or heart failure hospitalization (HFH) by gender and treatment arm.

Cumulative time-to-first-event curves for patients randomly assigned to MRA vs placebo by gender. Estimates for men and women are displayed in red and blue, respectively.

Figure 2. Kaplan-Meier survival curves for cardiovascular death (CVD) or heart failure hospitalization (HFH) by gender and treatment arm.

Cumulative time-to-first-event curves for patients randomly assigned to MRA vs placebo by gender in heart failure patients with LVEF $\leq 35 \%$ (panel A) and in heart failure patients with $L V E F \geq 45 \%$ (panel B).

Figure 3. Forest plot with crude and adjusted HRs for for cardiovascular death (CVD) or heart failure hospitalization by gender

Adjusted HRs are plotted in this figure, although both unadjusted and adjusted HR are reported in the right side. Model adjusted for MRA, gender, age, systolic blood pressure, diabetes, hypertension, atrial fibrillation, non-ischemic cause, NYHA class III-IV, LVEF, potassium, estimated glomerular filtration rate, ACEI or ARB, beta-blockers and the interaction (MRA x gender).

This article is protected by copyright. All rights reserved. 
Figure 4. Adjusted HRs for cardiovascular death or heart failure hospitalization by gender and other relevant groups

P-values correspond to three-way interactions using the adjusted model - i.e. MRA x gender $x$ diabetes

This article is protected by copyright. All rights reserved. 


\section{Tables}

Table 1. Baseline clinical features by sex (pooled data across the three trials)

\begin{tabular}{|c|c|c|c|}
\hline & Male $(n=4229)$ & Female $(n=1938)$ & p-value \\
\hline \multicolumn{4}{|l|}{ Study } \\
\hline EMPHASIS, n (\%) & 2127 (50.3\%) & $610(31.5 \%)$ & $<0.001$ \\
\hline RALES, n (\%) & $1217(28.8 \%)$ & $446(23.0 \%)$ & \\
\hline TOPCAT-Americas, n (\%) & $885(20.9 \%)$ & $882(45.5 \%)$ & \\
\hline \multicolumn{4}{|l|}{ Demographic data } \\
\hline Age (years), mean (SD) & $67.8(9.6)$ & $70.1(10.1)$ & $<0.001$ \\
\hline Age > 75 y.o., n (\%) & $1070(25.3 \%)$ & $686(35.4 \%)$ & $<0.001$ \\
\hline White race, $\mathrm{n}(\%)$ & $3612(85.4 \%)$ & $1479(76.3 \%)$ & $<0.001$ \\
\hline Body mass index $\left(\mathrm{kg} / \mathrm{m}^{2}\right)$, mean (SD) & $29.2(6.1)$ & $31.7(8.4)$ & $<0.001$ \\
\hline Current smoker, $\mathrm{n}(\%)$ & $1168(38.8 \%)$ & $170(11.4 \%)$ & $<0.001$ \\
\hline \multicolumn{4}{|l|}{ Vital signs } \\
\hline Heart rate (bpm), mean (SD) & $73.5(13.9)$ & $73.6(13.1)$ & 0.730 \\
\hline Systolic blood pressure (mmHg), mean (SD) & $123.5(17.2)$ & $126.9(18.5)$ & $<0.001$ \\
\hline Diastolic blood pressure (mmHg), mean (SD) & $73.7(10.8)$ & $73.6(11.5)$ & 0.730 \\
\hline \multicolumn{4}{|l|}{ Medical history } \\
\hline Hypertension, n (\%) & $2441(57.8 \%)$ & $1359(70.1 \%)$ & $<0.001$ \\
\hline Diabetes, n (\%) & $1354(32.0 \%)$ & $661(34.1 \%)$ & 0.110 \\
\hline Previous MI, n (\%) & $1866(44.2 \%)$ & $557(28.7 \%)$ & $<0.001$ \\
\hline Atrial Fibrillation / Flutter, n (\%) & $1114(26.5 \%)$ & $390(20.2 \%)$ & $<0.001$ \\
\hline COPD, n (\%) & $675(16.0 \%)$ & $234(12.1 \%)$ & $<0.001$ \\
\hline \multicolumn{4}{|l|}{ Heart failure history } \\
\hline Left ventricular ejection fraction, (\%) & $32.3(14.0)$ & $41.7(18.1)$ & $<0.001$ \\
\hline$\leq 35, n(\%)$ & 3218 (78.3\%) & $1024(53.7 \%)$ & $<0.001$ \\
\hline$>45 n(\%)$ & $886(21.6 \%)$ & $882(46.3 \%)$ & \\
\hline \multicolumn{4}{|l|}{ NYHA class } \\
\hline$I I, n(\%)$ & $2726(64.6 \%)$ & $1153(59.6 \%)$ & $<0.001$ \\
\hline$I I I-I V, n(\%)$ & 1497 (35.5\%) & $782(40.4 \%)$ & \\
\hline Previous HF hospitalisation & $1653(54.9 \%)$ & $826(55.4 \%)$ & 0.790 \\
\hline \multicolumn{4}{|l|}{ Laboratory tests } \\
\hline Hemoglobin (g/dL), mean (SD) & $13.7(2.0)$ & $12.6(2.2)$ & $<0.001$ \\
\hline Potassium (mmol/L), mean (SD) & $4.3(0.4)$ & $4.2(0.5)$ & $<0.001$ \\
\hline Sodium (mmol/L), mean (SD) & $139.5(4.4)$ & $139.7(3.6)$ & 0.190 \\
\hline MDRD eGFR, $\mathbf{m l} / \mathbf{m i n} / \mathbf{1 . 7 3} \mathrm{m}^{2}$ & $68.4(22.9)$ & $62.7(21.4)$ & $<0.001$ \\
\hline MDRD eGFR<60, n (\%) & 1608 (38.3\%) & $988(51.8 \%)$ & $<0.001$ \\
\hline \multicolumn{4}{|l|}{ Medications } \\
\hline ACEI or ARBs, n (\%) & 3830 (90.6\%) & $1666(86.0 \%)$ & $<0.001$ \\
\hline Beta blockers, n (\%) & $2698(63.8 \%)$ & $1224(63.2 \%)$ & 0.620 \\
\hline Diuretic, n (\%) & 3779 (89.4\%) & $1745(90.0 \%)$ & 0.430 \\
\hline Digoxin, n (\%) & $1292(38.6 \%)$ & $442(41.9 \%)$ & 0.062 \\
\hline Lipid lowering drug, n (\%) & 2064 (48.8\%) & $894(46.1 \%)$ & 0.050 \\
\hline Anti thrombotics, n (\%) & $2892(68.4 \%)$ & $1136(58.6 \%)$ & $<0.001$ \\
\hline
\end{tabular}

ACEI, angiotensin-converting-enzyme-inhibitors; AF, atrial fibrillation; ARB, angiotensin-receptor blockers; $B P$, blood pressure; $C O P D$, chronic obstructive pulmonary disease; eGFR, estimated Glomerular Filtration Rate; HF, heart failure; LVEF, left ventricular ejection fraction; MDRD, Modification of Diet in Renal Disease; MI, myocardial infarction; MRA; mineral receptor antagonist; NYHA, New York Heart Association

This article is protected by copyright. All rights reserved. 
Table 2. Time at risk, number of events and estimated incidence rates (95\% CI) for the primary endpoint (cardiovascular mortality or heart failure hospitalization)

\begin{tabular}{|c|c|c|c|c|c|}
\hline & $\begin{array}{c}\text { Total } \\
\text { person-time } \\
\text { at risk }\end{array}$ & $\begin{array}{c}\text { Number of } \\
\text { events }\end{array}$ & $\begin{array}{c}\text { Incidence rate } \\
\text { (95\% CI) }\end{array}$ & $\begin{array}{l}\text { Incidence rate } \\
\text { ratio }(95 \% \mathrm{CI})\end{array}$ & $\begin{array}{c}\text { Absolute } \\
\text { difference in } \\
\text { rates }(95 \% \mathrm{CI})\end{array}$ \\
\hline \multicolumn{6}{|c|}{ HFrEF (RALES+EMPHASIS-HF) } \\
\hline $\begin{array}{l}\text { Male-Placebo } \\
\text { Male-MRA }\end{array}$ & $\begin{array}{l}2528.7 \\
2755.1\end{array}$ & $\begin{array}{l}648 \\
471\end{array}$ & $\begin{array}{l}25.6(23.7-27.7) \\
17.1(15.6-18.7)\end{array}$ & $0.67(0.59-0.75)$ & $8.5(6.0-11.0)$ \\
\hline $\begin{array}{l}\text { Female-Placebo } \\
\text { Female-MRA }\end{array}$ & $\begin{array}{l}788.3 \\
897.5\end{array}$ & 200 & $\begin{array}{l}25.4(22.1-29.1) \\
15.6(13.2-18.4)\end{array}$ & $0.61(0.49-0.77)$ & $9.8(5.4-14.1)$ \\
\hline \multicolumn{6}{|c|}{ HFpEF (TOPCAT-Americas) } \\
\hline $\begin{array}{l}\text { Male-Placebo } \\
\text { Male-MRA }\end{array}$ & $\begin{array}{l}1081.9 \\
1149.6\end{array}$ & $\begin{array}{l}150 \\
131\end{array}$ & $\begin{array}{l}13.9(11.8-16.3) \\
11.3(9.5-13.5)\end{array}$ & $0.82(0.65-1.05)$ & $2.5(-0.5-5.4)$ \\
\hline $\begin{array}{l}\text { Female-Placebo } \\
\text { Female-MRA }\end{array}$ & $\begin{array}{l}1146.9 \\
1204.4\end{array}$ & $\begin{array}{l}130 \\
111\end{array}$ & $\begin{array}{l}11.4(9.6-13.5) \\
9.2(7.7-11.1)\end{array}$ & $0.81(0.63-1.06)$ & $2.1(-0.5-4.7)$ \\
\hline \multicolumn{6}{|l|}{ Overall } \\
\hline $\begin{array}{l}\text { Male-Placebo } \\
\text { Male-MRA }\end{array}$ & $\begin{array}{l}3610.5 \\
3904.7\end{array}$ & $\begin{array}{l}798 \\
602\end{array}$ & $\begin{array}{l}22.1(20.6-23.7) \\
15.4(14.2-16.7)\end{array}$ & $0.70(0.63-0.78)$ & $6.7(4.7-8.7)$ \\
\hline $\begin{array}{l}\text { Female-Placebo } \\
\text { Female-MRA }\end{array}$ & $\begin{array}{l}1935.2 \\
2101.9\end{array}$ & $\begin{array}{l}330 \\
251\end{array}$ & $\begin{array}{l}17.1(15.3-19.0) \\
11.9(10.6-13.5)\end{array}$ & $0.70(0.59-0.83)$ & $5.1(2.8-7.5)$ \\
\hline
\end{tabular}

By-trial and overall estimated incidence rates and absolute differences in rates for the primary endpoint. Total person-time at risk is expressed in 100 person-year. 
Table 3. Time at risk, number of events and estimated incidence rates (95\% CI) for the secondary endpoint (cardiovascular death)

\begin{tabular}{|c|c|c|c|c|c|}
\hline & $\begin{array}{c}\text { Total } \\
\text { person-time } \\
\text { at risk }\end{array}$ & $\begin{array}{l}\text { Number } \\
\text { of events }\end{array}$ & $\begin{array}{c}\text { Incidence rate } \\
\text { (95\% CI) }\end{array}$ & $\begin{array}{l}\text { Incidence rate } \\
\text { ratio }(95 \% \mathrm{CI})\end{array}$ & $\begin{array}{c}\text { Absolute } \\
\text { difference in } \\
\text { rates }(95 \% \mathrm{CI})\end{array}$ \\
\hline \multicolumn{6}{|c|}{ HFrEF (RALES+EMPHASIS-HF) } \\
\hline $\begin{array}{l}\text { Male-Placebo } \\
\text { Male-MRA }\end{array}$ & $\begin{array}{l}2958.7 \\
3046.7\end{array}$ & $\begin{array}{l}402 \\
311\end{array}$ & $\begin{array}{l}13.6(12.3-15.0) \\
10.2(9.1-11.4)\end{array}$ & $0.75(0.65-0.87)$ & $3.4(1.6-5.1)$ \\
\hline $\begin{array}{l}\text { Female-Placebo } \\
\text { Female-MRA }\end{array}$ & $\begin{array}{l}939.1 \\
994.1\end{array}$ & $\begin{array}{l}121 \\
84\end{array}$ & $\begin{array}{l}12.9(10.8-15.4) \\
8.5(6.8-10.5)\end{array}$ & $0.66(0.49-0.87)$ & $4.4(1.5-7.4)$ \\
\hline \multicolumn{6}{|c|}{ HFpEF (TOPCAT-Americas) } \\
\hline $\begin{array}{l}\text { Male-Placebo } \\
\text { Male-MRA }\end{array}$ & $\begin{array}{l}1271.1 \\
1302.7\end{array}$ & $\begin{array}{l}69 \\
56\end{array}$ & $\begin{array}{l}5.4(4.3-6.9) \\
4.3(3.3-5.6)\end{array}$ & $0.79(0.55-1.14)$ & $1.1(-0.01-2.8)$ \\
\hline $\begin{array}{l}\text { Female-Placebo } \\
\text { Female-MRA }\end{array}$ & $\begin{array}{l}1331.8 \\
1360.5\end{array}$ & $\begin{array}{l}58 \\
40\end{array}$ & $\begin{array}{l}4.4(3.4-5.6) \\
2.9(2.2-4.0)\end{array}$ & $0.68(0.44-1.03)$ & $1.4(0.0-2.9)$ \\
\hline \multicolumn{6}{|l|}{ Overall } \\
\hline $\begin{array}{l}\text { Male-Placebo } \\
\text { Male-MRA }\end{array}$ & $\begin{array}{l}4229.8 \\
4349.4\end{array}$ & 367 & $\begin{array}{c}11.1(10.2-12.2) \\
8.4(7.6-9.3)\end{array}$ & $0.76(0.66-0.87)$ & $2.7(1.3-4.0)$ \\
\hline $\begin{array}{l}\text { Female-Placebo } \\
\text { Female-MRA }\end{array}$ & $\begin{array}{l}2270.9 \\
2354.5\end{array}$ & $\begin{array}{l}179 \\
124\end{array}$ & $\begin{array}{l}7.9(6.8-9.1) \\
5.3(4.4-6.3)\end{array}$ & $0.67(0.53-0.84)$ & $2.6(1.1-4.1)$ \\
\hline
\end{tabular}

By-trial and overall estimated incidence rates and absolute differences in rates for cardiovascular mortality. Total person-time at risk is expressed in 100 person-year. 
Table 4. Time at risk, number of events and estimated incidence rates (95\% CI) for the secondary endpoints all-cause death

\begin{tabular}{|c|c|c|c|c|c|}
\hline & $\begin{array}{c}\text { Total } \\
\text { person-time } \\
\text { at risk }\end{array}$ & $\begin{array}{l}\text { Number } \\
\text { of events }\end{array}$ & $\begin{array}{c}\text { Incidence rate } \\
\text { (95\% CI) }\end{array}$ & $\begin{array}{l}\text { Incidence rate } \\
\text { ratio }(95 \% \mathrm{CI})\end{array}$ & $\begin{array}{c}\text { Absolute } \\
\text { difference in } \\
\text { rates }(95 \% \mathrm{CI})\end{array}$ \\
\hline \multicolumn{6}{|c|}{ HFrEF (RALES+EMPHASIS-HF) } \\
\hline $\begin{array}{l}\text { Male-Placebo } \\
\text { Male-MRA }\end{array}$ & $\begin{array}{l}2958.7 \\
3046.7\end{array}$ & $\begin{array}{l}460 \\
360\end{array}$ & $\begin{array}{l}15.5(14.2-17.0) \\
11.8(10.7-13.1)\end{array}$ & $0.76(0.66-0.87)$ & $3.7(1.9-5.6)$ \\
\hline $\begin{array}{l}\text { Female-Placebo } \\
\text { Female-MRA }\end{array}$ & $\begin{array}{l}939.1 \\
994.1\end{array}$ & 139 & $\begin{array}{l}14.8(12.5-17.5) \\
9.8(8.0-11.9)\end{array}$ & $0.66(0.50-0.86)$ & $5.0(1.9-8.2)$ \\
\hline \multicolumn{6}{|c|}{ HFpEF (TOPCAT-Americas) } \\
\hline $\begin{array}{l}\text { Male-Placebo } \\
\text { Male-MRA }\end{array}$ & $\begin{array}{l}1271.1 \\
1302.7\end{array}$ & 112 & $\begin{array}{l}8.4(7.0-10.2) \\
8.6(7.1-10-3)\end{array}$ & $1.02(0.78-1.34)$ & $-0.2(-2.4-2.1)$ \\
\hline $\begin{array}{l}\text { Female-Placebo } \\
\text { Female-MRA }\end{array}$ & $\begin{array}{l}1331.8 \\
1360.5\end{array}$ & $\begin{array}{l}98 \\
70\end{array}$ & $\begin{array}{l}7.4(6.0-9.0) \\
5.1(4.1-6.5)\end{array}$ & $0.70(0.51-0.96)$ & $2.2(0.3-4.1)$ \\
\hline \multicolumn{6}{|l|}{ Overall } \\
\hline $\begin{array}{l}\text { Male-Placebo } \\
\text { Male-MRA }\end{array}$ & $\begin{array}{l}4229.8 \\
4349.4\end{array}$ & $\begin{array}{l}567 \\
472\end{array}$ & $\begin{array}{c}13.4(12.3-14.6) \\
10.9(9.9-11.9)\end{array}$ & $0.81(0.71-0.92)$ & $2.5(1.14 .0)$ \\
\hline $\begin{array}{l}\text { Female-Placebo } \\
\text { Female-MRA }\end{array}$ & $\begin{array}{l}2270.9 \\
2354.5\end{array}$ & $\begin{array}{l}237 \\
167\end{array}$ & $\begin{array}{c}10.4(9.2-11.9) \\
7.1(6.1-8.3)\end{array}$ & $0.68(0.55-0.83)$ & $3.3(1.6-5.1)$ \\
\hline
\end{tabular}

By-trial and overall estimated incidence rates and absolute differences in rates for all-cause mortality. Total person-time at risk is expressed in 100 person-year. 
Table 5. Side effects within treatment arm by sex (pooled data across the three trials)

\begin{tabular}{|c|c|c|c|c|c|c|c|}
\hline & & MRA & & & Placebo & & $\begin{array}{l}\text { p for } \\
\text { interaction }\end{array}$ \\
\hline $\begin{array}{l}\text { HFrEF } \\
\text { (RALES+EMPHASIS-HF) }\end{array}$ & $\begin{array}{c}\text { Male } \\
(n=1,658)\end{array}$ & $\begin{array}{l}\text { Female } \\
(n=528)\end{array}$ & $\begin{array}{c}\text { p- } \\
\text { value }\end{array}$ & $\begin{array}{c}\text { Male } \\
(\mathbf{n}=\mathbf{1 , 6 8 6})\end{array}$ & $\begin{array}{l}\text { Female } \\
(n=528)\end{array}$ & P-value & \\
\hline $\begin{array}{l}\text { Hyperkalemia, n } \\
\text { (\%) }\end{array}$ & 241 (14.9\%) & $71(1.0 \%)$ & 0.617 & 115 (7.0\%) & $37(7.2 \%)$ & 0.891 & 0.683 \\
\hline $\begin{array}{l}\text { Worsening renal } \\
\text { function, } n(\%)\end{array}$ & 446 (28.9\%) & 165 (33.7\%) & 0.040 & 311 (20.0\%) & 123 (25.3\%) & 0.012 & 0.630 \\
\hline $\begin{array}{l}\text { HFpEF } \\
\text { (TOPCAT-Americas) }\end{array}$ & $\begin{array}{c}\text { Male } \\
(n=444)\end{array}$ & $\begin{array}{l}\text { Female } \\
(n=442)\end{array}$ & $\begin{array}{c}\text { p- } \\
\text { value }\end{array}$ & $\begin{array}{c}\text { Male } \\
(n=441)\end{array}$ & $\begin{array}{l}\text { Female } \\
(n=440)\end{array}$ & P-value & \\
\hline $\begin{array}{l}\text { Hyperkalemia, n } \\
\text { (\%) }\end{array}$ & 73 (16.5\%) & 68 (15.4\%) & 0.657 & $22(5.0 \%)$ & $24(5.5 \%)$ & 0.762 & 0.625 \\
\hline $\begin{array}{l}\text { Worsening renal } \\
\text { function, } n(\%)\end{array}$ & 175 (39.4\%) & $214(48.5 \%)$ & 0.006 & 129 (29.3\%) & 160 (36.4\%) & 0.025 & 0.811 \\
\hline Overall & $\begin{array}{c}\text { Male } \\
(n=2,102)\end{array}$ & $\begin{array}{l}\text { Female } \\
(n=970)\end{array}$ & $\begin{array}{c}\text { p- } \\
\text { value }\end{array}$ & $\begin{array}{c}\text { Male } \\
(n=2,127)\end{array}$ & $\begin{array}{l}\text { Female } \\
(n=968)\end{array}$ & P-value & \\
\hline $\begin{array}{l}\text { Hyperkalemia, n } \\
\text { (\%) }\end{array}$ & 314 (15.2\%) & 139 (14.7\%) & 0.679 & $137(6.6 \%)$ & $61(6.4 \%)$ & 0.840 & 0.944 \\
\hline $\begin{array}{l}\text { Worsening renal } \\
\text { function, n (\%) }\end{array}$ & $621(31.2 \%)$ & 379 (40.8\%) & $<0.001$ & $440(22.0 \%)$ & 283 (30.6\%) & $<0.001$ & 0.813 \\
\hline
\end{tabular}

Hyperkalemia was defined as any laboratory value of serum potassium above $5.5 \mathrm{mmol} / \mathrm{L}$ during the follow-up. Worsening renal function was defined as an estimated glomerular filtration rate drop greater than 30\% during the follow-up. Within gender comparison were made using the chi-square test, whereas differences in adverse event effects were tested using the interaction (MRA * gender) in a logistic regression. The hypothesis of little heterogeneity is also supported by the Wald test for overall interaction study $\mathrm{x}$ treatment $\mathrm{x}$ gender for both hyperkalemia $(\mathrm{p}=0.85)$ and worsening renal function $(\mathrm{p}=0.84)$. 
Unadjusted HR $(95 \% \mathrm{Cl})$

Adjusted

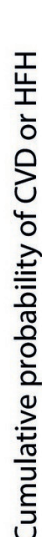

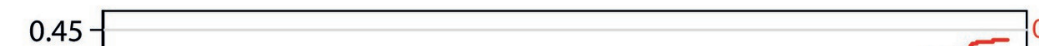

$0.69(0.62-0.77)$

(HR 95\% Cl)

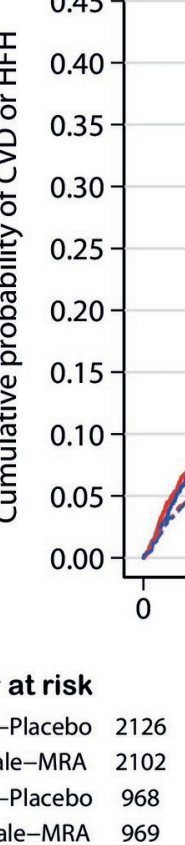

0.71

$0.71(0.60-0.83) \quad 0.73(0.62-0.86)$

Number at risk

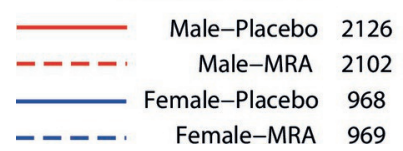

$(0.62-0.77)$

This article is protected by copyright. All rights reserved. 


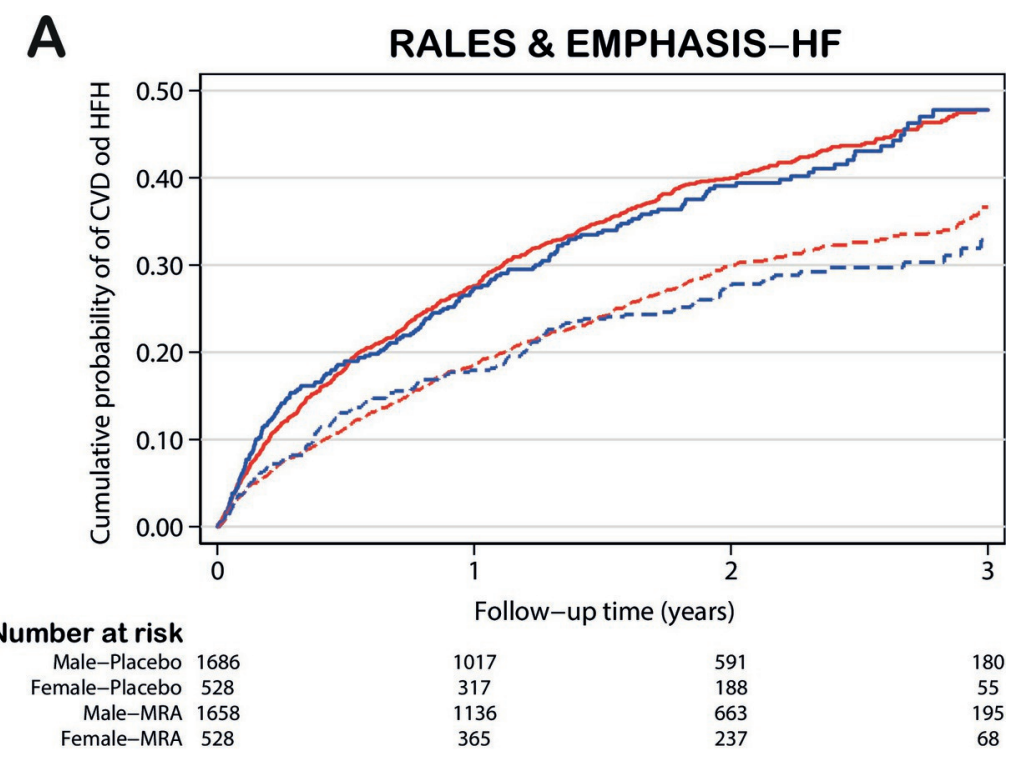

Female-MRA 528

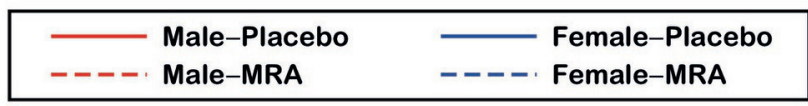

B

TOPCAT-Americas

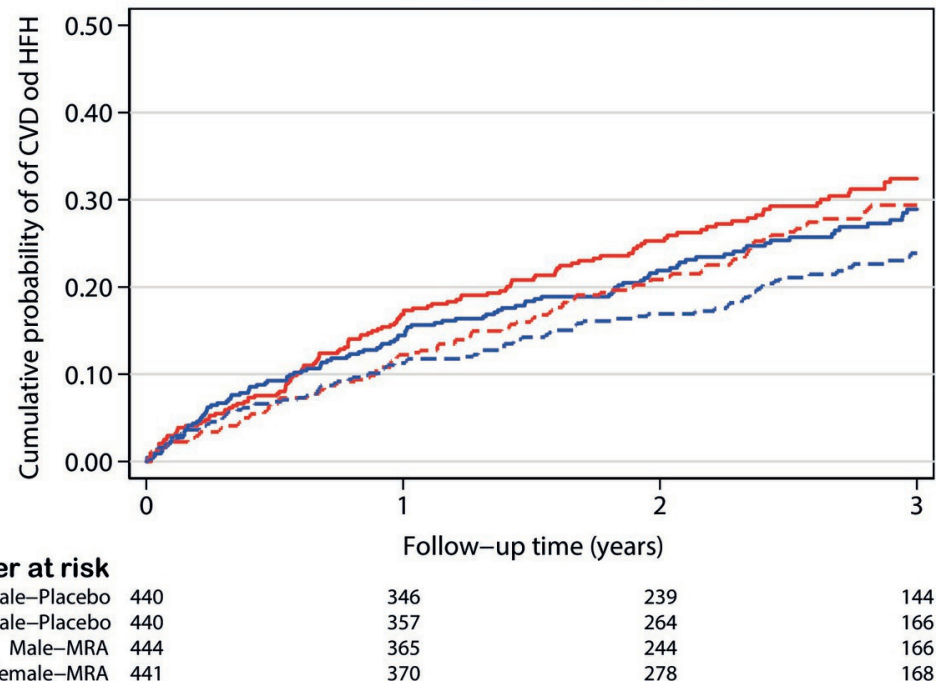

fig 2 - km - gender r1.eps

This article is protected by copyright. All rights reserved. 


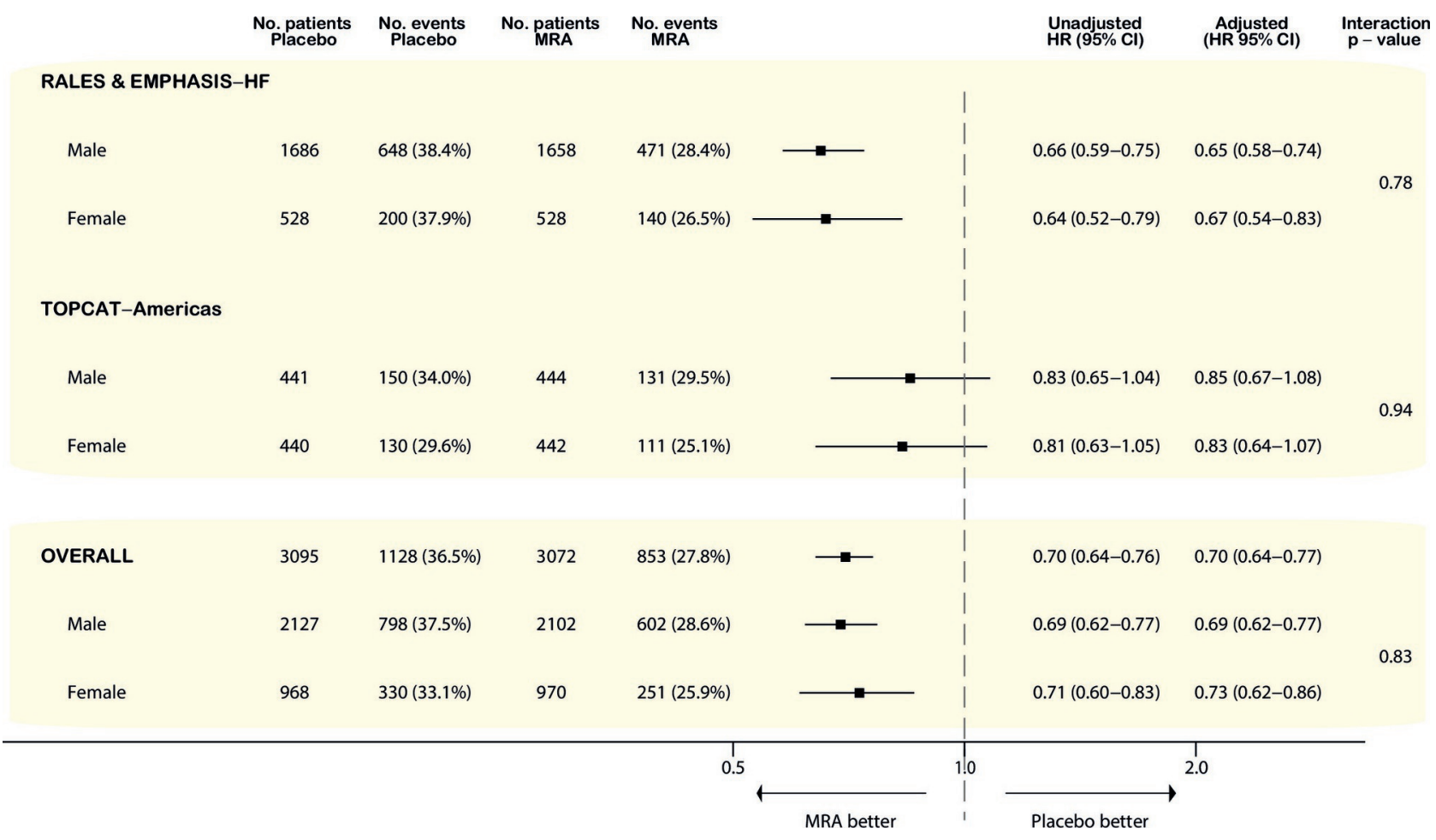

fig 3 - fplot - gender r1.eps 


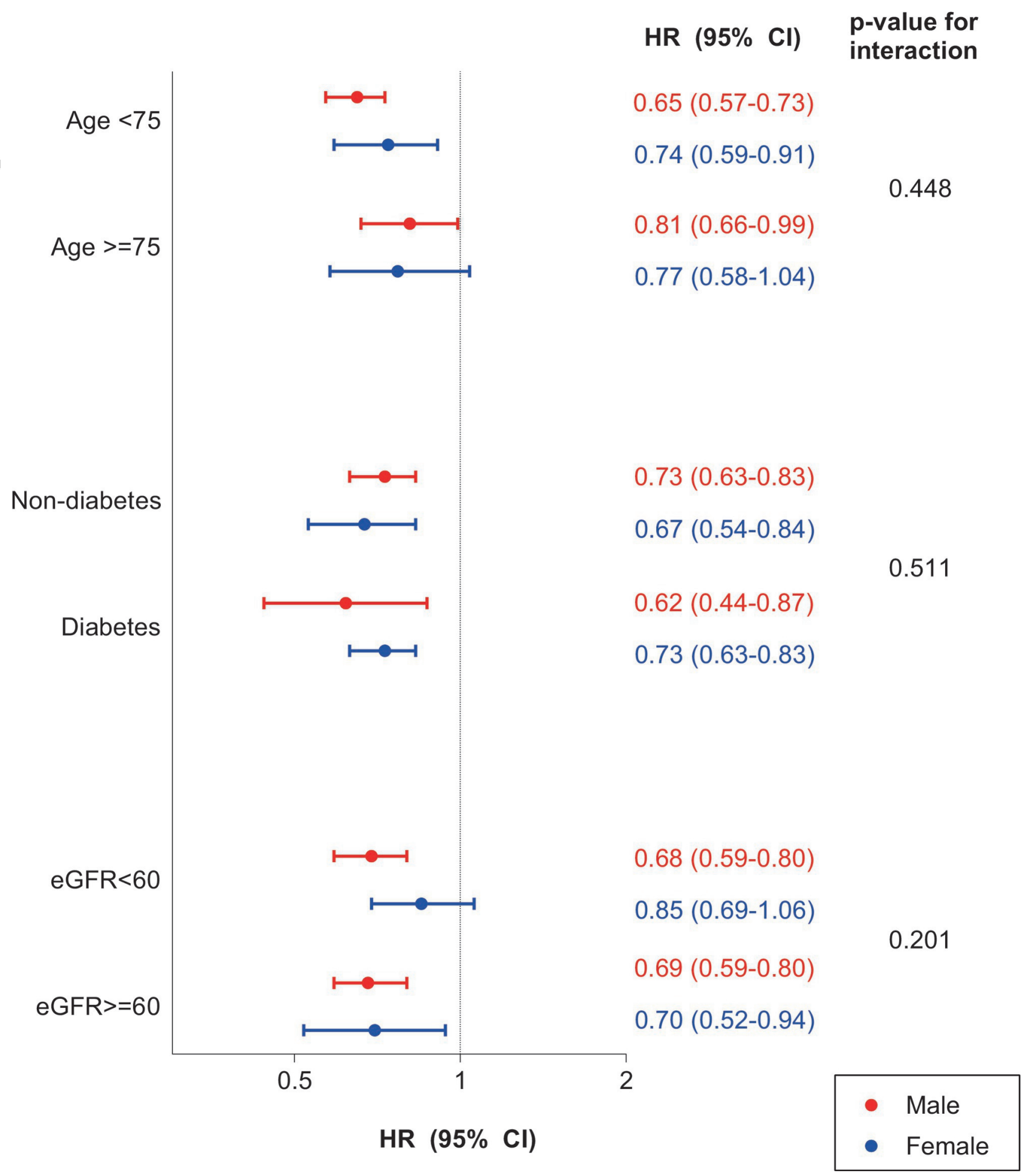

fig 4 - fplot - gender r1.eps 
The material contained in this paper has not been previously published and it is not under consideration for publication in any journal. All authors have read and approved the present version of the manuscript. 